\title{
PENANGKAPAN IKAN DENGAN CARA MENGESAR LEBUNG DI LUBUK LAMPAM, SUMATERA SELATAN
}

\author{
Burnawi ${ }^{1)}$ \\ 1) Teknisi Litkayasa pada Balai Riset Perikanan Perairan Umum, Mariana-Palembang \\ Teregristasi I tanggal: 15 Agustus 2006; Diterima setelah perbaikan tanggal: 4 Juni 2007; \\ Disetujui terbit tanggal: 13 Agustus 2007
}

\section{PENDAHULUAN}

Perairan lubuk lampam (luas \pm 1.200 ha) adalah bagian dari daerah aliran Sungai Lempuing letak 25 $\mathrm{km}$ sebelah tenggara kota Kayu Agung yang merupakan ibu kota Kabupaten Ogan Komering llir. daerah aliran Sungai Lempuing sendiri adalah perairan yang bersifat rawa lebak lebung flood flain yang sekaligus merupakan daerah penangkapan ikan bagi Kabupaten Ogan Komering llir (Arifin Z., 1978).

Lebung adalah suatu cekungan tanah yang terbentuk secara alami atau yang dibuat oleh manusia dengan ukuran luas 100 sampai dengan $2.000 \mathrm{~m}$ dan dalam 1 sampai dengan $3 \mathrm{~m}$, daerah ini akan tergenang di musim hujan dan pada musim kemarau berfungsi sebagai tempat berkumpul ikan. Di Sumatera Selatan masyarakat mengatakan lebung dan di Kalimantan disebut beje.

Prasetyo, (1996) mengatakan bahwa cara penangkapan ikan dengan cara mengesar lubuk di perairan lubuk lampam merupakan cara menangkap ikan secara tradisional dan sudah berlangsung sejak lama yang dilakukan oleh para nelayan di waktu musim kemarau. Alat bantu penangkapan yang dipakai adalah empang bilah atau jaring krakat, tetapi sekarang para nelayan lebih suka menggunakan alat bantu penangkapan jaring krakat karena lebih praktis dan tahan lama.

Mengesar lebung adalah suatu kegiatan menangkap ikan di perairan sungai dengan cara mempersempit ruang gerak ikan menggunakan alat bantu jaring krakat atau empang bilah. Pada musim kemarau yakni bulan Agustus sampai dengan September.

Tujuan penulisan makalah adalah mengetahui cara penangkapan ikan dengan cara mengesar lebung di perairan lubuk lampam Kabupaten Ogan Komering Ilir, Sumatera Selatan.

\section{POKOK BAHASAN}

Penangkapan ikan dengan cara mengesar lebung di lubuk lampam (Gambar 1) memakai alat bantu jaring krakat, ada beberapa pokok bahasan antara lain bahan, alat, dan cara kerja.

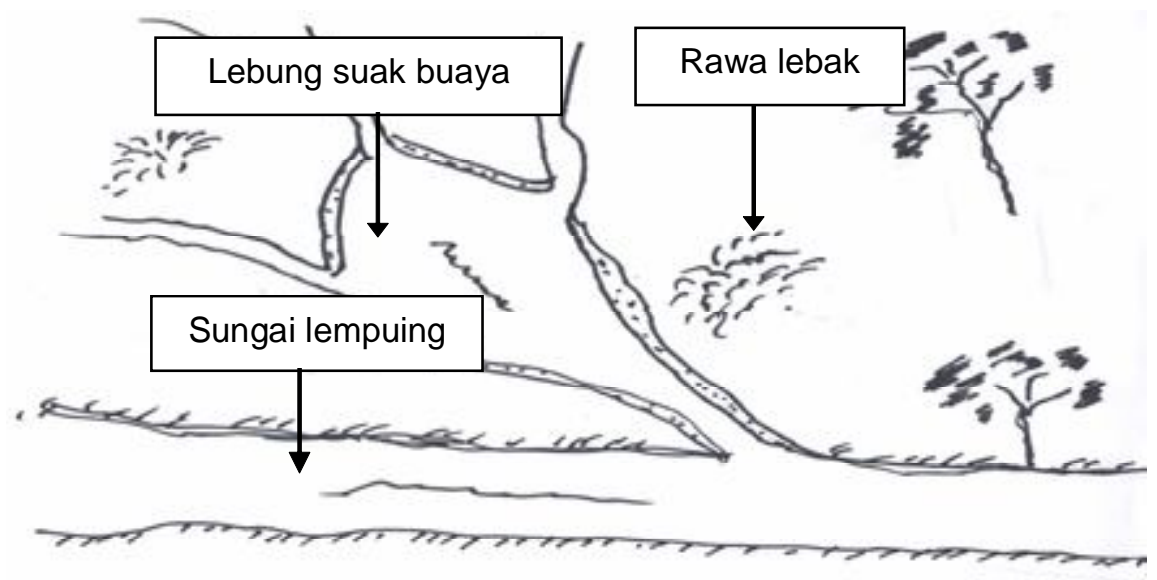

Gambar 1. Sketsa lebung suak buaya di perairan lubuk lampam.

\section{Bahan}

Bahan terdiri atas kayu dan tali plastik.

\section{Alat}

Alat terdiri atas krakat, jala tebar, pisau, serok, perahu kayu, dan perahu motor. Jaring krakat adalah alat bantu penangkapan ikan terbuat dari tali atau benang nilon dengan ukuran mata jaring 0,5 sampai dengan $1 \mathrm{~cm}$, diberi pemberat terbuat dari rantai besi dan diberi pelampung dengan jarak 50 sampai dengan $75 \mathrm{~cm}$, lebar $6 \mathrm{~m}$, dan panjang berkisar 30 sampai dengan $50 \mathrm{~m}$ atau tergantung dengan kebutuhan (Gambar 2). 


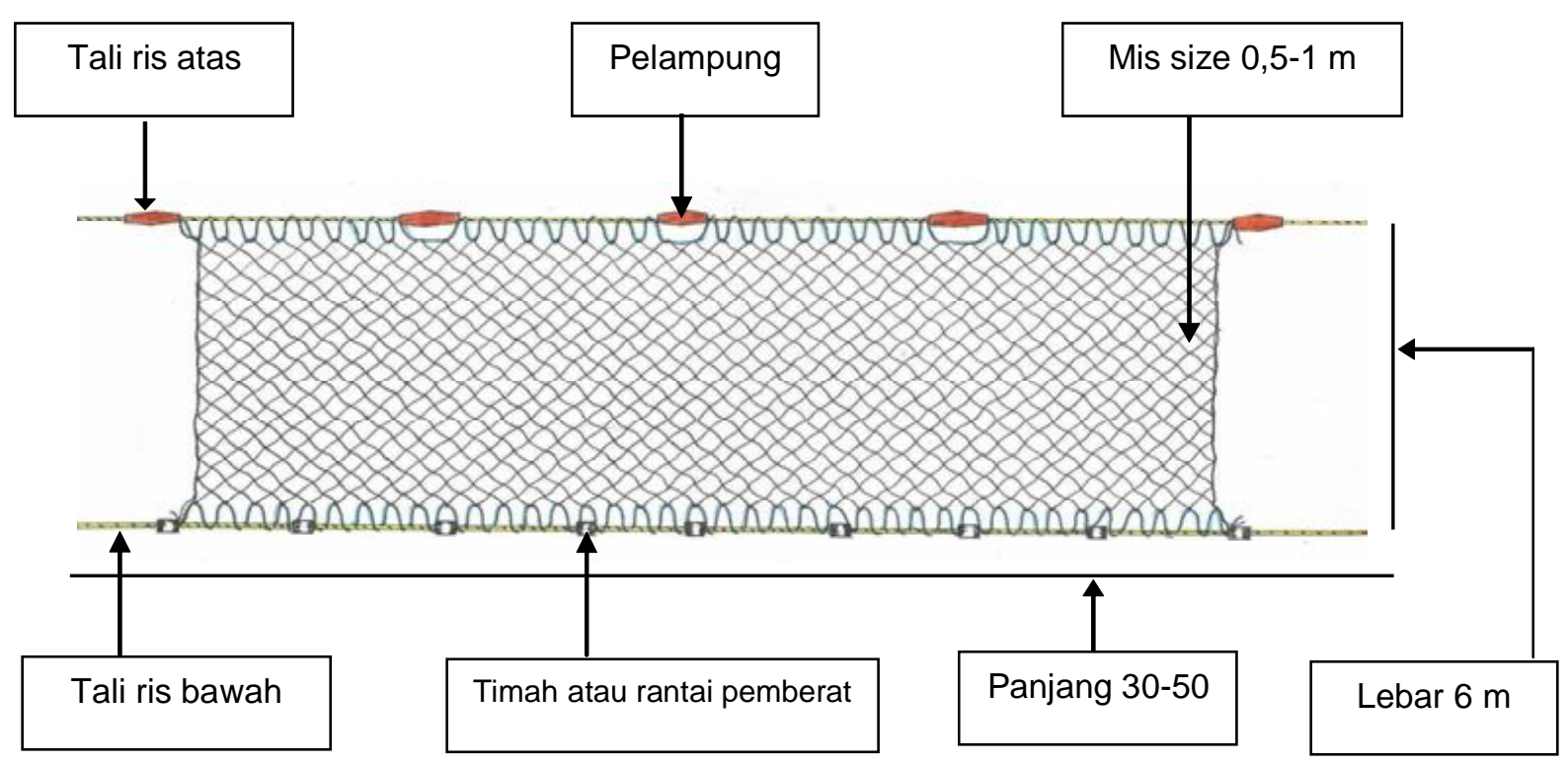

Gambar 2. Jaring krakat

\section{CARA KERJA}

\section{Pembersihan Lebung}

Sebelum melakukan kegiatan penangkapan ikan dengan cara mengesar, lebung dibersihkan terlebih dahulu dari ranting-ranting kayu dan tumbuhan air seperti kumpai dan enceng gondok (Eichhornia crassipes) dengan cara ditebas menggunakan parang panca (pisau) dimulai dari tepi lebung sampai dengan ke tengah lebung yang dikerjakan oleh 4 sampai dengan 8 orang.

Tumbuhan air yang telah ditebas disingkirkan ke tepi lebung dengan cara ditarik menggunakan perahu. Pekerjaan ini dilakukan selama 4 sampai dengan 7 hari tergantung dengan luasan dan kepadatan tumbuhan air.

\section{Pengoperasian Alat}

Pada saat mengesar lebung nelayan dibagi menjadi 2 kelompok. Kelompok I: menarik jaring krakat dan kelompok II: menangkap ikan dengan jala tebar. Di sisi bagian belakang jaring krakat para nelayan kelompok II secara bersama-sama menangkap ikan menggunakan alat tangkap jala tebar. Adapun cara mengesar adalah tali ris jaring krakat bagian bawah ditarik perlahan-lahan secara bersama-sama yang dipimpin oleh 1 orang nelayan untuk memberikan abaaba agar jaring krakat tersebut ditarik dari bagian hilir lebung mengarah ke hulu lebung secara perlahanlahan yang membentuk setengah melingkar. Bila jarak jaring krakat $\pm 2 \mathrm{~m}$ dari tepi lebung, maka penarikkan tersebut dihentikan karena ruang gerak ikan sudah semakin sempit, kemudian tali ris jaring krakat bagian atas diikatkan pada tonggak kayu dan tali ris bagian bawah dijepit dengan pating (patok kayu) yang ditancapkan ke dalam tanah dengan kedalaman 30 sampai dengan $50 \mathrm{~cm}$ dan jarak antara pating 1 sampai dengan $2 \mathrm{~m}$ (Gambar 3).

\section{Pengambilan Ikan}

Pengambilan ikan dilakukan dengan menggunakan serok, kemudian ikan-ikan tersebut ditampung di dalam perahu motor. Bila diperkirakan ikan sudah tidak begitu banyak lagi di dalam jaring krakat, maka jaring krakat ditarik sampai dengan daratan tepi lebung dan ikan yang ada dalam jaring krakat diharapkan tertangkap semua (Gambar 4).

Ikan-ikan yang tertangkap disortir berdasarkan pada jenis ikan. Para pedagang pengepul telah siap untuk membeli ikan hasil tangkapan nelayan.

\section{Hasil Tangkapan}

Hasil tangkapan dengan cara mengesar di lebung suak buayo lubuk lampam Kabupaten Ogan Komering Ilir, Sumatera Selatan terdiri atas sepat siam (Trichogaster pectoralis), gabus (Channa striata), palau (Osteochilus hasselti), damain (Thynnichthys polylepis), baung (Mystus nemurus), lais (Kryptopterus $\mathrm{sp}$.), betok (Anabas testudineus) berengit (Mystus nigriceps), tambakan (Helostoma temmincki), putak (Notopterus notopterus), seberas (Cyclocheilicthys apogon), sepat mata abang (Trichogaster trichopterus), betutu (Oxyeleotris mamoratus), keli (Clarias melanoderma), dan sebarau (Hampala macrolepidota) (Tabel 1). 


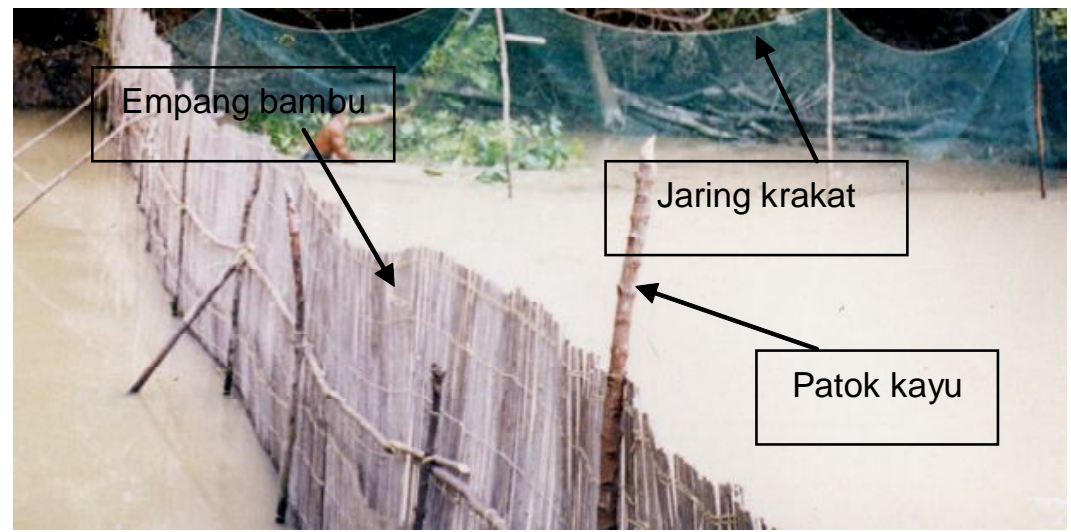

Gambar 3. Pada saat ngesar lebung

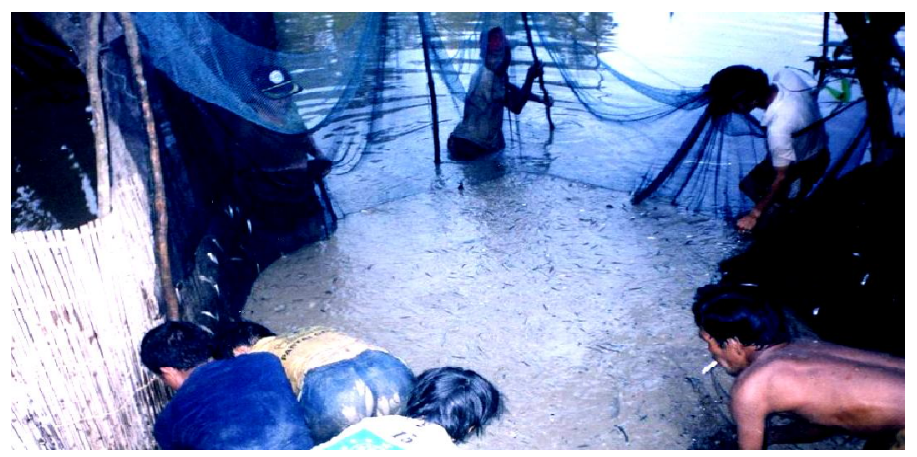

Gambar $4 . \quad$ Penarikan jaring krakat ke tepi lebung

Tabel 1. Komposisi jenis ikan di suaka perikanan suak buaya di lubuk lampam Kabupaten Ogan Komering Ilir, Sumatera Selatan, tahun 2001

\begin{tabular}{llcc}
\hline \multirow{2}{*}{ Nama lokal } & \multicolumn{1}{c}{ Nama Ilmiah/Latin } & \multicolumn{2}{c}{ Komposisi hasil tangkapan } \\
\cline { 3 - 4 } & & $\begin{array}{c}\text { Bobot } \\
(\mathbf{k g})\end{array}$ & $\begin{array}{c}\text { Jumlah } \\
(\%)\end{array}$ \\
\hline Sepat siam & Trichogaster pectoralis & 428 & 20,4 \\
Gabus & Channa striata & 274 & 13 \\
Palau & Osteochilus hasselti & 233 & 11 \\
Damain & Thynnichthys polylpis & 102 & 4,8 \\
Baung & Mystus nemurus & 106 & 5 \\
Lais & Kryptopterus sp, & 146 & 7 \\
Betok & Anabas testudineus & 286 & 13,6 \\
Berengit & Mystus nigriceps & 102 & 4,8 \\
Tambakan & Helostoma temmincki & 176 & 8,4 \\
Putak & Notopterus notopterus & 81 & 3,8 \\
Seberas & Cyclocheilicthys apogon & 18 & 0,85 \\
Sepat mata abang & Trichogaster trichopterus & 132 & 6,3 \\
Betutu & Oxyeleotris mamoratus & 6 & 0,55 \\
Keli & Clarias melanoderma & 4,2 & 0,3 \\
Sebarau & Hampala marcrolepidota & 2 & 0,2 \\
\hline Jumlah & & $\mathbf{2 . 0 9 5 , 2}$ & $\mathbf{1 0 0 , 0}$ \\
\hline
\end{tabular}

Dari data di atas menunjukkan bahwa jenis ikan yang tertangkap di perairan lubuk suak buaya ada 14 jenis tetapi yang dominan berdasarkan pada bobot biomassa adalah ikan sepat siam, betok, gabus, dan palau.

\section{KESIMPULAN}

1. Teknik penangkapan ikan dengan cara mengesar lebak lebung cukup baik yang dilakukan oleh nelayan. 
2. Jenis ikan yang tertangkap di lebung suak buayo di perairan lubuk lampam Kabupaten Ogan Komering llir, Sumatera Selatan ada 14 jenis ikan, adapun yang dominan adalah ikan sepat siam, betok, gabus, dan palau.

\section{DAFTAR PUSTAKA}

Arifin, Z. 1978. Beberapa aspek tentang penangkapan ikan di perairan lubuk lampam. Simposium Moderenisasi Perikanan Rakyat. Lembaga Penelitian Perikanan Darat Cabang Palembang. Jakarta. 27-30 Juni 1978.
Prasetyo, D. \& A. D. Utomo. 1996. Pelestarian sumber daya plasmah nutfah perairan umum. Jurnal Penelitian dan Pengembangan Pertanian $X$. (4): 90-96.

Utomo, A. D, Asyari, \& S. Nurdawati. 2001. Peranan suaka perikanan dalam peningkatan dan pelestarian sumber daya perikanan perairan umum: Studi kasus di suaka perikanan suak buaya, Kabupaten Ogan Komering Ilir, Sumatera Selatan. Jurnal Penelitian Perikanan Indonesia. Vol.7 No.1. Hal.1-9. Pusat Riset perikanan Budi Daya. Badan Riset Kelautan dan Perikanan. Departemen Kelautan dan Perikanan. Jakarta. 


\section{Lampiran 1. Peta Kabupaten Ogan Komering Ilir}

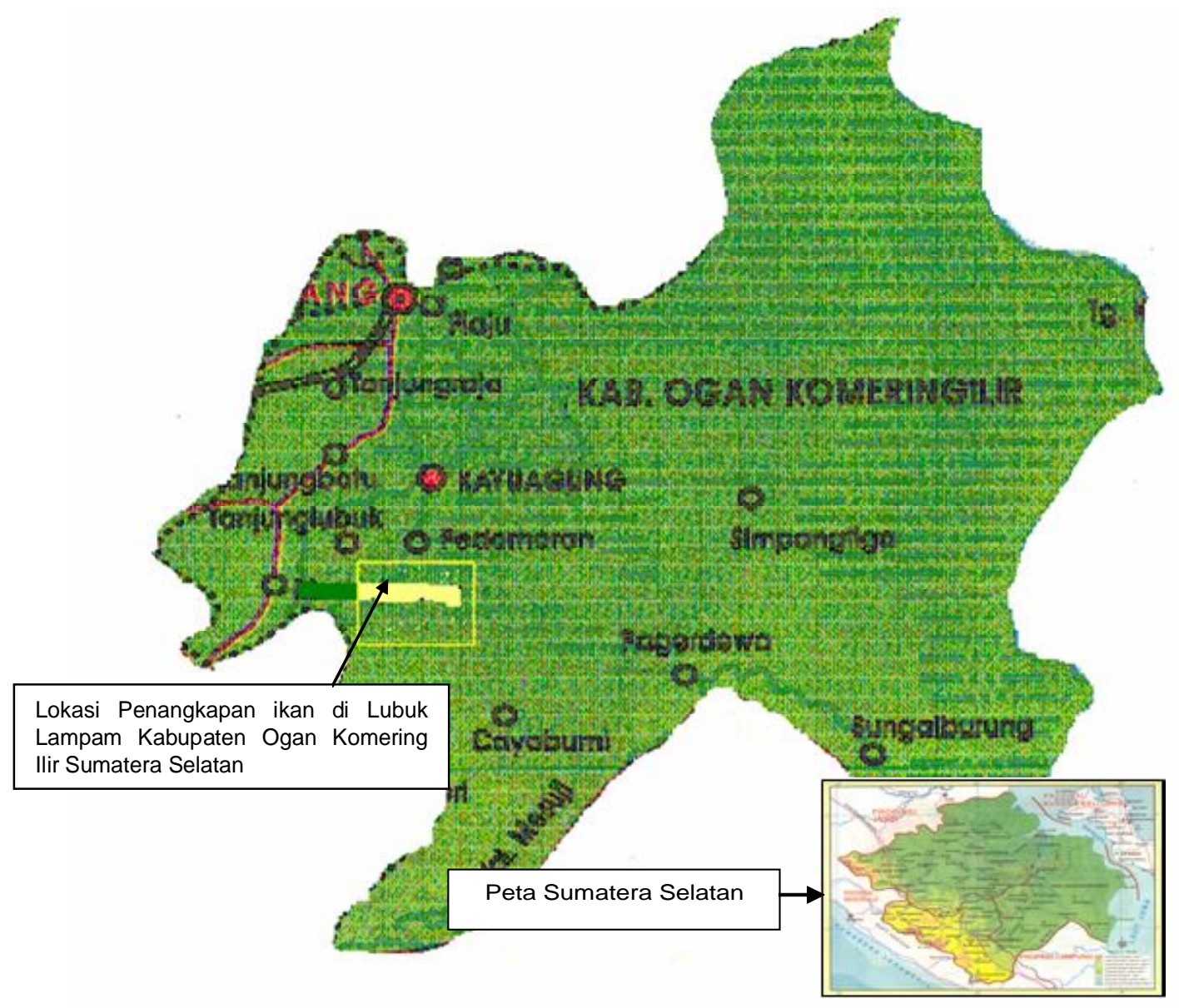

Lampiran 2. Peta lokasi penangkapan ikan di lubuk lampam

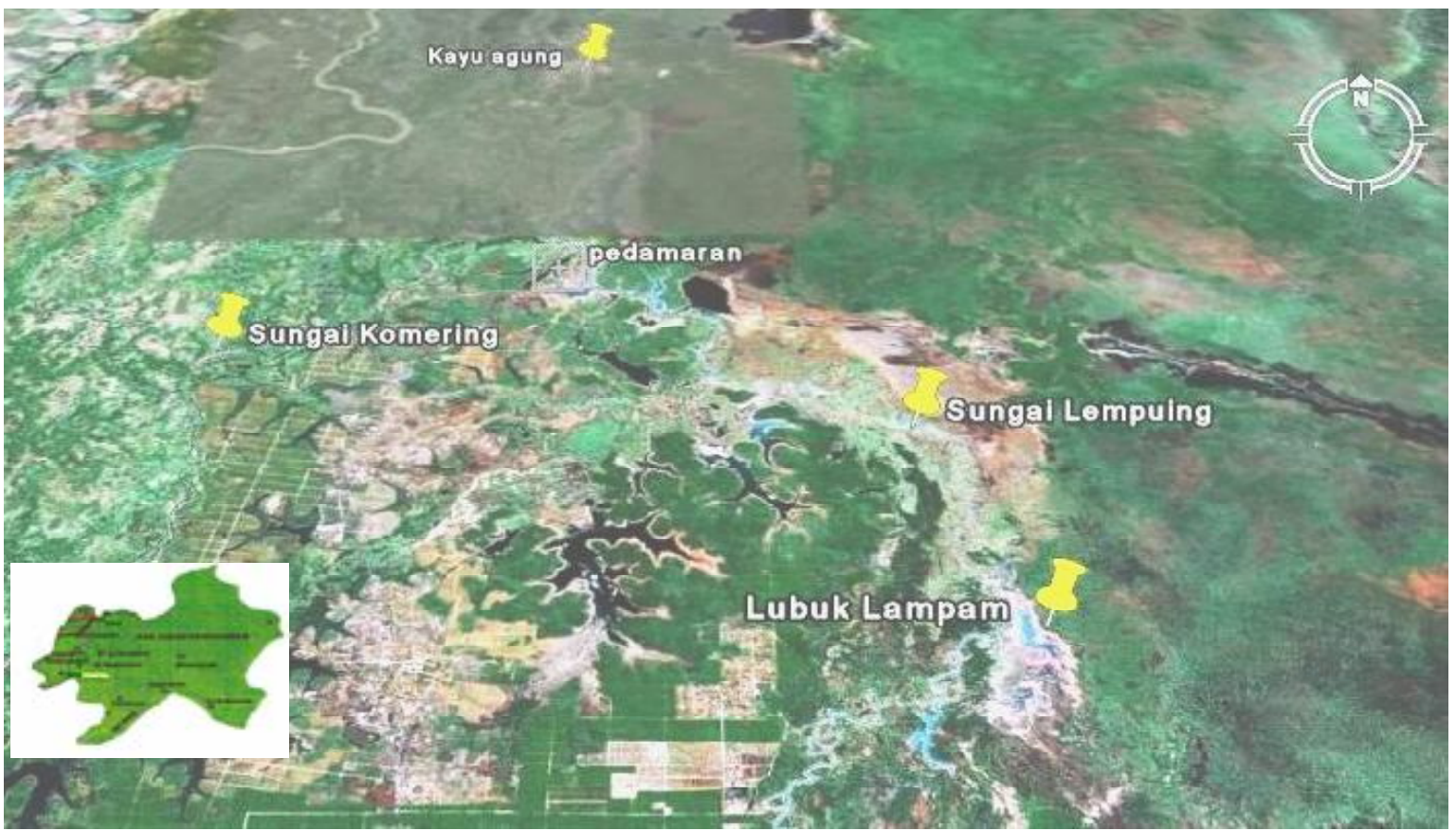

